\title{
ON SOME PROPERTIES OF STRICTLY CONVEX FUNCTIONS
}

\author{
WITOLD JARCZYK AND KAZIMIERZ NIKODEM
}

Abstract. We prove that some careless modification of the definition of strong convexity leads to a condition which is equivalent to that one of strict convexity.

Mathematics subject classification (2010): 26A51, 39B62.

Keywords and phrases: Strict convexity, strong convexity.

\section{REFERENCES}

[1] M. V. Jovanovič, A note on strongly convex and strongly quasi-convex functions, Math. Notes 60 (1996), 778-779.

[2] L. MONTRUCCHIO, Lipschitz continuous policy functions for strongly concave optimization problems, J. Math. Econom. 16 (1987), 259-273.

[3] C. P. Niculescu And L.-E. Persson, Convex Functions and their Applications. A Contemporary Approach, CMS Books in Mathematics vol. 23, Springer-Verlag, New York, 2006.

[4] K. Nikodem, On strongly convex functions and related classes of functions, in: T. M. Rassias (ed.) Handbook of functional equations, 365-405, Springer Optim. Appl. 95, Springer, New York, 2014.

[5] E. S. Polovinkin, Strongly convex analysis, Sb. Math. 187 (1996), 259-286.

[6] B. T. POLYAK, Existence theorems and convergence of minimizing sequences in extremum problems with restrictions, Sov. Math. Dokl. 7 (1966), 72-75.

[7] A. W. Roberts and D. E. Varberg, Convex functions, Academic Press, New York-London, 1973.

[8] J. P. Vial, Strong and weak convexity of sets and functions, Math. Oper. Res. 8 (1983), 231-259. 